relatively recent appreciation of the fact that perforating vessels were capable of sustaining a large variety of flaps.

The first volume gives detailed accounts of flap types, anatomy and physiology and overall provides an excellent account of the basic principles underlying perforator flaps. This volume also includes chapters on planning and complications. The latter of these gives a very clear account of the main 'golden rules' for complication avoidance in this type of surgery. The remainder of this volume is divided into three sections dealing with flaps of the head and neck, upper extremity and trunk.

The first section of the second volume deals with flaps of the lower extremity followed by a good account of the clinical applications of a wide range of perforator flaps for reconstruction in various sites of the body.

The final part of the second volume is, in my view, one of the most interesting sections of the entire book. Entitled 'Controversies and Future Directions', this explores a number of newer concepts, including that of the 'freestyle free flap' (a flap harvested from any region of the body, based on a vessel identified by Doppler), 'supermicrosurgery' (vessels of $0.5-0.8 \mathrm{~mm}$ ) and neurocutaneous perforator flaps.

The quality of the presentation and illustration is high throughout. As with most multi-author texts there is invariably some overlap in the various chapters, but this is a minor criticism. I have no doubt that this two-volume set would be a significant asset to any individual or department involved in reconstructive surgery and I recommend it highly.

\section{The Art of Aesthetic Surgery: Principles and Techniques}

FOAD NAHAI

$\begin{array}{ll}\text { EXTENT P/H } & 2,500 \mathrm{p} \text {, hardback } \\ \text { PRICE/ISBN } & \text { US } \$ 875.00 \quad 1576261778 \\ \text { PUBLISHER } & \text { Quality Medical Publishing (Missouri), } 2005 \\ \text { REVIEWER } & \text { Chris Khoo } \\ \text { STAR RATING } & * * * * *\end{array}$

Foad Nahai qualified in medicine at Bristol and completed his surgical training in Baltimore and Atlanta. His career progressed through assistant and associate professorships in plastic surgery and to a full chair in 1991. An incisive thinker, he published with Stephen Mathes in 1982 what immediately became the standard classification of the vascular anatomy of muscle. He has co-authored seven books, encompassing reconstructive surgery, breast cancer, muscle flaps and endoscopic surgery. His breadth of experience has been focused for most of the last decade on aesthetic surgery and this three-volume text is the result.

The author's academic background is apparent in the way that the information is organised. The entire field is systematically presented but the general and wide-ranging knowledge is made intensely practical. The scientific basis of each specialised topic is developed through chapters on clinical decision-making, challenges to practice and even advice on dealing with colleagues who present themselves for cosmetic surgery, some with the expectation that their surgery will be free! There is advice on the law in the US and on how to manage a practice. The author has himself written a third of the 65 chapters and the book brings together 73 contributors with special expertise in their invited topics. The text is lavishly illustrated with colour drawings and photographs, and five DVDs are packaged in.

Individual topics are exhaustively covered, with 11 chapters on face-lift procedures alone. The logical approach applied to each subject is helpful, working through patient education and assessment, pertinent anatomy, pre-operative planning, operative technique, postoperative care, avoidance of complications and the evaluation of results. 'Clinical caveats' are distilled from experience and are presented as bullet points. Chapters conclude with an annotated bibliography where references are presented with a brief critique and further suggested readings covering the literature.

This is a complete work. Operative and non-operative cosmetic treatments are all dealt with and information is presented both critically and within context. The author's depth of knowledge is complemented by sagacity: 'In my experience, surgical judgement is the critical element that separates a good aesthetic result from a great one'. Dr Nahai has succeeded brilliantly in his aim of creating a comprehensive work that is 'aesthetically appealing, clinically relevant and user-friendly'. It will be the most valuable reference for all aesthetic surgeons and may well become the single most useful source for surgeons of any level of experience. This book should be on the shelf of every surgeon involved in this exacting field.

\section{Medicall Emergencies for Finals}

PRASANNA SOORIAKUMARAN, CHANNA JAYASENA, ANJLA SHARMAN

\begin{tabular}{ll}
\hline EXTENT P/H & 288p, paperback \\
PRICE/ISBN & $£ 21.95 \quad 1857757475$ \\
PUBLISHER & Radcliffe (Oxford), 2006 \\
REVIEWER & Zarina Shaikh \\
STAR RATING & $* * *$
\end{tabular}

The quest of all discerning final-year medical students is to make some clinical sense of the volumes of facts that they have methodically memorised over the preceding years of study. This book has been written with this aim in mind. Its objective is to fill in 'the gaps in the learner's knowledge 
about the practicalities of treatment' through the provision of 'easily digested and clear advice on emergencies'. The authors have drawn the content from their own experience in medical, surgical and general practice. The target population for this book includes medical students, foundation trainees, emergency nurse practitioners and pre-hospital personnel.

The layout is very logical with each chapter focusing on a particular specialty. The topics included are those most likely to be encountered during a routine week in the accident and emergency department. Within each chapter each subsection is divided into clinical features, aetiology and management with an accompanying list of references for further reading. This format is virtually uniform throughout the book, which makes it very helpful to the pre-examination candidate in search of a structured system of learning. However, this format has been deviated from in the few surgical sections and, at an initial glance, appears a little wordy. Nevertheless, closer reading reveals valuable and relevant information conforming to the objectives of the book.

In the context of aetiology of the conditions included there is a focus on the most common factors rather than comprehensive lists and this is appropriate for the target reader. A very pleasing component in most chapters is the inclusion of algorithmic strategies of management based on the current evidence base. This is particularly applicable to the foundation trainee and junior accident and emergency doctor. The use of clear and relevant diagrams, mnemonics and validated scoring systems also makes this book a useful aid to candidates preparing for higher examinations.

In the context of practical treatment, it would have been helpful to see more details on the precise techniques of skills such as catheterisation and chest-drain insertion, which medical students are expected to have an understanding of in the OSCE examination setting. Description of medical management and stabilisation of patients is excellent in this book, with helpful suggestions of appropriate medications to use. The bullet-pointed format of the treatment sections is delineated in a logical fashion, making them directly applicable to the clinical scenario.

Comparing this book to other revision aids for final-year students, the strengths include its logical structure, clarity of presentation and breadth of specialties covered. With its content taking account of only the most common conditions, it helps to focus the final-year student on the reality of day-to-day practice instead of the frequent fascination with the rare and bizarre. The main weakness in comparison to other similar-style books such as the Sprigings and Chambers book on Acute Medicine and the Oxford Handbook of Acute Medicine is that it lacks the essential knowledge of detailed practical procedures that both finalyear medical students and foundation trainees need to manage the emergency scenario effectively. I do, however, feel that it is a very useful adjunct to revision for the final-year student preparing for a viva voce style OSCE examination.

\section{Orthopedic Traumatology - A Resident's Guide}

IP DAVID

$\begin{array}{ll}\text { EXTENT P/H } & 571 \mathrm{p}, \text { paperback } \\ \text { PRICE/ISBN } & £ 30.50 \quad 3540290656 \\ \text { PUBLISHER } & \text { Springer (Berlin), 2006 } \\ \text { REVIEWER } & \text { Bill Ryan } \\ \text { STAR RATING } & * * *\end{array}$

According to Dr Ip's preface, his book is aimed at doctors in training and, where appropriate, paramedical staff who regularly deal with trauma victims. With relevance to the UK, this will mainly mean FY2, ST1 and ST2 doctors. It has forewords and is essentially endorsed by two eminent trauma professors, namely Charles Court-Brown from Edinburgh and John Wedge from Toronto.

The book is divided into 12 chapters discussing important areas of trauma management. It is written in the style of a thesis, with nearly every paragraph numbered and subdivided so that a detailed index is given at the beginning of each chapter. I felt that this division for a textbook was too detailed as the point of an index at the start of a chapter is to give an at-a-glance guide to what is in it. This was not possible here as some chapter indices are many pages long. The main index at the end of the book is in a standard format and is accurate. Most topics are easy to find using the index. However, some are mentioned on many different pages and it is not clear in the index where the main narrative is located. For example, compartment syndrome has 16 entries, none of which are highlighted for ease of access.

Each topic is presented in bullet-point format with any necessary subdivisions and the topics covered are accurate and current. Some of the basics like requesting appropriate radiographs, the management of major trauma and the principles of fracture fixation are described well. The current issues in fracture management and the ideas put forward are clearly contemporary and, overall, the material covered is relevant with no serious omissions.

Illustrations are lacking in number and do not always appear close to the relevant text. I felt some of the text used was difficult to understand and a single diagram with a few words would have got the message across. On occasion, I felt the illustrations were not the best examples to go with the text. For example, in the section on periprosthetic fractures in the lower limb, major osteolysis around a complex knee implant is shown. A simpler example of, say, a fracture adjacent to a total knee prosthesis, which is seen much more commonly would have illustrated the point better. 